\title{
Image-Guidance in Endonasal Endoscopic Excision of Different Fibro-Osseous Pathologies of Paranasal Sinuses and Skull Base
}

\author{
Ali Al Momen ${ }^{1 *}$, Mohammad Al Eid ${ }^{2}$, Zainab Ali ${ }^{1}$, Ahmed Alnabi ${ }^{1}$, Amirah Aldhurais ${ }^{1}$, Balsam Alawami ${ }^{1}$ and Zahra \\ Almoumen ${ }^{1}$ \\ ${ }^{1}$ Senior Consultant, Rhinology and Skull Base Surgery, King Fahd Specialist Hospital, Saudi Arabia
}

${ }^{2}$ ENT Resident, Saudi Commission of Health Specialties, Eastern Province Program, Saudi Arabia

Submission: August 09, 2020; Published: September 02, 2020

*Corresponding author: Ali Almomen, Senior consultant, Rhinology \& Skull Base Surgery, ENT department, KFSH, Dammam, Saudi Arabia

\begin{abstract}
Background: Osteoma, fibrous, dysplasia and ossifying fibroma are fibro-osseus lesions that can occur in the paranasal sinuses, management of these lesions can be technically challenging due to proximity to the orbit and skull base, with the advancement in endoscopic endonasal surgery and development of technologies such as image guidance can improve the safety of endoscopic removal and improve its safety.

Illustrative cases: Three cases of fibro-ossuoes lesions are presented in this study an adult female with left frontoethmoidal osteoma, an adult male with left ethmoid fibrous dysplasia, both of whom have been treated with pure endonasal endoscopic approach with image guidance, the third case is a male child with juvenile ossifying fibroma, he was treated initially with the endoscopic approach with image guidance, but had a skull base recurrence 6 months later which was removed with an open craniotomy approach.

Conclusion: Image guidance is a valuable tool in improving safety and efficiency of endoscopic sinus surgery particularly in challenging cases such as fibro-osseus lesions with proximity to the skull base and orbit.
\end{abstract}

Keywords: Image guidance; Osteoma; Endoscopic surgery

\section{Introduction}

Benign Fibro-osseous lesions in the paranasal sinuses are divided into three different types: Osteoma, Ossifying fibroma and fibrous dysplasia, these lesions share similar clinical and pathological features, and although they are considered benign, they can lead to significant symptoms due to the anatomical location of paranasal sinuses and proximity to the orbit and cranial cavity.

Conservative management with follow up and serial imaging is advocated for asymptomatic cases, and surgical intervention is reserved for complicated lesions and symptomatic patients. Since the introduction of endoscopic sinus surgery, endoscopic approach has been the standard of care for most sinus pathologies, yet, management of sino-nasal fibro-osseous lesions remains technically challenging, because of distorted anatomy loss of intranasal landmarks, and extensive involvement of skull base or orbits, In such cases image-guidance systems can provide the surgeon with useful information regarding the location of surgical instrumentation and the extent of bone removal along the skull base. The purpose of this study is to present our experience with image-guided technology for endoscopic treatment of different fibro-osseous lesions of Paranasal sinuses.

\section{Illustrative cases}

\section{Case 1 osteoma}

A 31 years old female, presented with history of chronic nasal obstruction, headache, with history of recurrent episodes of acute sinusitis, endoscopic nasal examination was clear, CT scan showed an osteoma involving the left frontoethmoidal region with attachments to the orbit and the skull base, endoscopic removal of the osteoma was done with image guidance for drilling of orbital and skull base attachments, (Figure 1) there was no postoperative complications and the patient has been following up in the clinic for 3 years with no signs of recurrence. 


\section{Global Journal of Otolaryngology}

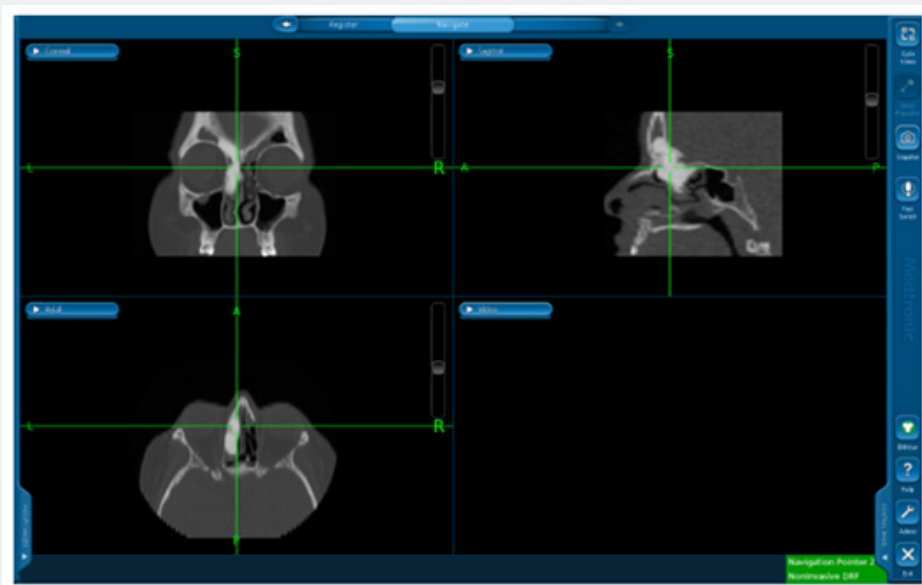

Figure 1: Intra-operative image guided CT images for endoscopic removal of left front-ethmoidal osteoma, demonstrating the attachment to the left orbit and skull base.

\section{Case 2 fibrous dysplasia}

A 34 years old male, presented to our clinic with chronic history of left sided facial pain, nasal obstruction and headache, no history of epistaxis or visual disturbances, physical examination revealed a large mass in the left nasal cavity displacing the nasal septum and middle turbinate to the right. CT scan showed the large mass centered in the left anterior ethmoid sinus, measuring $3.7 \times 2.9 \mathrm{~cm}$ in the axial plane and $5.2 \mathrm{~cm}$ in the coronal plane, the mass has heterogenous density with a calcified rim peripherally and soft tissue density centrally, it resulted in bone remodeling with septal deviation to the right side, its medial aspect caused remodeling of the medial orbital cavity displacing the medial rectus muscle, it extended superiorly involving the frontal sinus, it was also invading the left cribriform plate with intracranial extension. Image guided endonasal endoscopic removal was done, the mass was adherent to the orbit and skull base (Figures 1 \& 2). Histopathology confirmed the diagnosis of fibrous dysplasia. The patient has been following in the outpatient department for 3 years with no signs of recurrence.

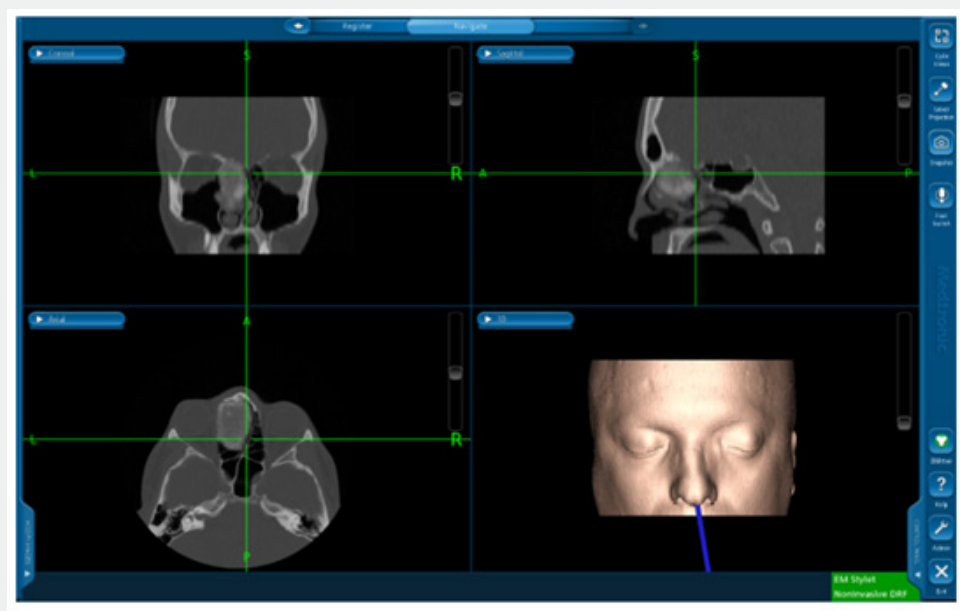

Figure 2: Intra-operative image guided removal of left ethmoid Fibrous Dysplasia.

\section{Case 3 ossifying fibroma}

A child who had history of right sided progressive nasal obstruction, hyposmia and proptosis for 10 months, there was no history of nasal discharge, and no visual disturbances, there was right sided proptosis on examination, nasal endoscopy revealed a large fleshy mass filling the right nasal cavity and pushing the nasal septum to the left side, CT scan showed a heterogamous expansible lesion involving right ethmoid pushing septum to left side and abutting the right eye. 
The mass was resected with navigation-assisted endoscopic endonasal approach, (Figure 3) histopathology confirmed the diagnosis of Juvenile ossifying fibroma. 6 months post operation on follow up, he has complaining of right sided headache and hyposmia, with no nasal obstruction, investigations revealed and extensive skull base recurrence, it was removed with an open craniotomy approach followed by skull base reconstruction. The patient has been following up for 3 years with no sign of recurrence on serial imaging and endoscopic examinations.

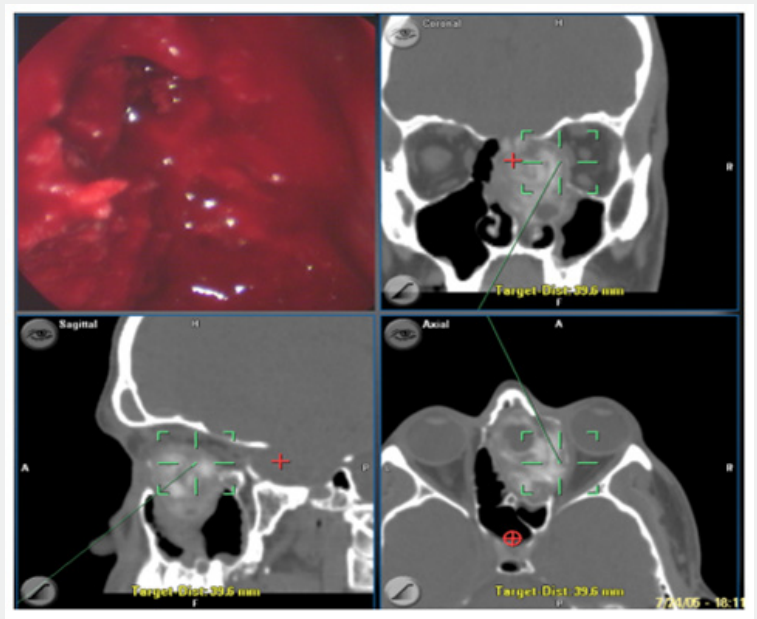

Figure 3: Intra-operative image guided removal of right ethmoid ossifying fibroma, demonstrating utility of localization technology to avoid potential orbital complications.

\section{Discussion}

\section{Osteoma}

Osteomas are the most common benign sino-nasal fibrosseous lesion, most commonly affecting the frontal and ethmoid sinuses [1]. Histological subtypes of osteoma are three: Ivory osteoma, which are mainly composed of lamellar bone with minimal fibrous tissue, mature osteomas, which contain trabecular bone with significant fibrous tissue, and mixed osteomas containing segments of both [2]. Osteomas are often asymptomatic and discovered incidentally, symptoms usually result from tumors that are large or those obstructing the sinus outflow tracts, patients may present with headache, chronic rhinosinusitis, mucoceles, cosmetic deformity, cerebrospinal fluid leak and meningitis.

CT imaging is the gold standard for assessment of osteoma, they appear as well-circumscribed, dense masses and could be homogenous or heterogenous based on histologic subtype, osteomas do not enhance with contrast CT studies [3]. Indications for surgical intervention include symptomatic tumors, intracranial or intra orbital involvement, growth of more than $1 \mathrm{~mm}$ per year on serial imaging [4]. Surgical options for paranasal sinus osteoma include external approach, endoscopic approach or combined approach using both methods, the size, location, and surgeon experience determines the approach for each case [5], for ethmoid sinus osteoma, endoscopic approach is relatively straightforward, however, for frontal sinus osteoma, the external approach was considered the standard approach [6].
The advent of new endoscopic equipment, such as angled scopes, angled drills and surgical navigation systems, and the accumulation of experience with endoscopic sinus surgery, have expanded the limits of endoscopic approaches, Chiu et al. [7] recommended endoscopic resection of small frontal osteomas medial to the sagittal line passing through the lamina papyracea (grade I and II), while using the external approach if the location was lateral to the sagittal line passing through the lamina papyracea or filling the frontal sinus (grade III and IV) [7]. However, Turri-Zanoni et al. [8] have successfully managed to treat 7 cases of osteomas with far lateral extension in the frontal sinus using purely endoscopic approach, suggesting that lateral extension beyond lamina papyracea is no longer an absolute contraindication of endoscopic removal as previously considered [8]. In the presented case the osteoma was involving the left frontoethmoidal region with grade 3 frontal sinus involvement, with the author's surgical experience and the availability of advanced equipment's the patient was successfully treated with pure endonasal endoscopic approach.

\section{Fibrous dysplasia}

It is a progressive disease caused by impaired proliferation and maturation of fibroblasts, resulting in replacement of mature bone with poorly structured immature fibro-osseous tissue, $25 \%$ of FD cases affect the head and neck region. There are three types of FD in the head and neck, the monostatic lesion, which is confined to one bone, polyostotic lesions involving different bones and as 
part of McCune-Albright's syndrome, a systemic disorder with endocrine dysfunction and abnormal cutaneous pigmentation [9]. The clinical presentation depends on the compression effect of the pathological bone on the adjacent structures, it can present as facial asymmetry, headache, epiphora, and visual disturbance due to optic nerve involvement. Diagnosis is based on clinical presentation and radiological work up including CT and MRI, CT imaging features matte-glass appearance, provides information regarding the extent of involvement, it is also efficient in assessment of cranial nerve entrapment and optic nerve compression.

On MRI, signal intensity on T1- and T2- weighted images is variable, depending on the amount of bone trabeculation and degree of cellularity, Characteristically, lesions show low signal intensity and well-demarcated borders on both T1- and T2weighted images [10] for asymptomatic patients with fibrous dysplasia, it is generally accepted to treat them conservatively with clinical and radiological follow up, surgical management is indicated for symptomatic and complicated cases Image guidance technology is particularly useful for treatment of fibrous dysplasia as it can distort intranasal anatomy and can be extensive, image guidance can provide information about thickness of remaining bone, that separates the instrument from the cranial or orbital contents, preventing injury to vital structures such as the dura, optic nerve or cavernous sinus. Wong et al. [9] reported their experience in managing 2 cases of Sino-nasal fibro-osseous lesions with image guidance and intra-operative CT, which revealed incomplete removal in a case of fibrous dysplasia that required additional excision, suggesting that intra-operative CTupdated image guidance in such cases can lead to a more optimal tumor control, potentially reducing the risk of recurrence with complete excision [11].

\section{Ossifying fibroma}

It is considered as a benign, locally aggressive neoplasm, it has variable biologic behavior though it was thought of as a slow growing tumor, as with other fibo-osseus lesions of paranasal sinuses, it is often discovered incidentally or when it has grown significantly causing facial distortion or compression of adjacent anatomic structures [12]. Several histopathological variants of ossifying fibroma have been described, including cementoossifying fibroma, juvenile active ossifying fibroma, and aggressive psammomatoid ossifying fibroma.

symptoms and signs include ptoptosis, diplopia, nasal obstruction, headache, examination could show smooth, rounded masses if the lesion involve the nasal cavity, complicated cases may present with vision loss, mucocele formation or intracranial infection.

Radiologic studies are important for diagnosis and surgical planning, the histological variants of ossifying fibroma cannot be reliably differentiated based on imaging as they have overlapping features even with magnetic resonance imaging studies, CT scan usually shows and eggshell-thin rim of bone surrounding a lytic area, on MRI, there is lo to intermediate intensity on T1 and variable intensity on T2 imaging, with contrast enhancement of the outer layer [13]. The treatment goal is complete surgical removal of the lesion, traditionally, external or microscopical approaches have been described, more recently, complete removal can be achieved with pure endoscopic approach with improved instruments, increased surgical experience, and the use of image guidance technology, [14] due to rarity of this disorder, there is no evidence suggesting which approach is superior to the other, the decision should be made based on the location of the lesion and the ability to perform complete removal safely. Post op surveillance for recurrence can be done with serial nasal endoscopy or yearly sinus CT [12].

\section{Conclusion}

Image guided technology is a valuable tool in management of sino-nasal fibro-osseus lesion, it has expanded some of the limitations of endonasal endoscopic surgery particularly in resection of lesions with close proximity to the orbit and skull base, image guidance can enhance the surgeon's confidence in performing more optimal removal of the tumor and improve the efficiency and safety of the endoscopic sinus surgery.

\section{Ethical Approval}

This research is approved by the institutional review board (IRB) at KFSH DAMMAM.

\section{References}

1. Castelnuovo P, Valentini V, Giovannetti F, Bignami M, Cassoni A, et al. (2008) Osteomas of the maxillofacial district: endoscopic surgery versus open surgery. J Craniofac Surg 19(6): 1446-1452.

2. Fu YS, Perzin KH (1974) Non-epithelial tumors of the nasal cavity, paranasal sinuses, and nasopharynx. A clinicopathologic study. II. Osseous and fibro-osseous lesions, including osteoma, fibrous dysplasia, ossifying fibroma, osteoblastoma, giant cell tumor, and osteosarcoma. Cancer 33(5): 1289-1305.

3. Eller R, Sillers M (2006) Common fibro-osseous lesions of the paranasal sinuses. Otolaryngol Clin North Am 39(3): 585-600.

4. Watley DC, Mong ER, Rana NA, Illing EA, Chaaban MR (2019) Surgical Approach to Frontal Sinus Osteoma: A Systematic Review. Am J Rhinol Allergy 33(5): 462-469.

5. Çelenk F, Baysal E, Karata ZA, Durucu C, Mumbuç S, et al. (2012) Paranasal sinus osteomas. J Craniofac Surg 23(5): e433-437.

6. Buyuklu F, Akdogan MV, Ozer C, Cakmak O (2011) Growth characteristics and clinical manifestations of the paranasal sinus osteomas. Otolaryngol head neck Surg 145(2): 319-323.

7. Chiu AG, Schipor I, Cohen NA, Kennedy DW, Palmer JN (2005) Surgical decisions in the management of frontal sinus osteomas. Am J Rhinol 19(2): 191-197.

8. Turri Zanoni M, Dallan I, Terranova P, Paolo Battaglia, Apostolos Karligkiotis, et al. (2012) Frontoethmoidal and intraorbital osteomas: exploring the limits of the endoscopic approach. Arch Otolaryngol Head Neck Surg 138(5): 498-504. 
9. Samaha M, Metson R (2003) Image-guided resection of fibro-osseous lesions of the skull base. Am J Rhinol 17(2): 115-118.

10. Amit M, Fliss DM, Gil Z (2011) Fibrous dysplasia of the sphenoid and skull base. Otolaryngol Clin North Am 44(4): 891-902.

11. Wong WK, Matsuwaki Y, Omura K, Moriyama H (2011) Role of intraoperative CT-updates during image-guided endoscopic sinus surgery for sinonasal fibro-osseous lesions. Auris Nasus Larynx 38(5): 628-631.
12. Manes RP, Ryan MW, Batra PS, Mendelsohn D, Fang Y V, et al. (2013) Ossifying fibroma of the nose and paranasal sinuses. Int Forum Allergy Rhinol 3(2): 161-168.

13. Kendi ATK, Kara S, Altinok D, Keskil S (2003) Sinonasal ossifying fibroma with fluid-fluid levels on MR images. AJNR Am J Neuroradiol 24(8): 1639-1641.

14. Appiani MC, Verillaud B, Bresson D, Sauvaget E, Blancal JP, et al. (2015) Fibroma ossificante dei seni paranasali: Diagnosi e management. Acta Otorhinolaryngol Ital 35(5): 355-361.

\begin{tabular}{l} 
Your next submission with Juniper Publishers \\
will reach you the below assets \\
- Quality Editorial service \\
- Swift Peer Review \\
- Reprints availability \\
- E-prints Service \\
- Manuscript Podcast for convenient understanding \\
- Global attainment for your research \\
- Manuscript accessibility in different formats \\
( Pdf, E-pub, Full Text, Audio) \\
- Unceasing customer service \\
Track the below URL for one-step submission \\
https://juniperpublishers.com/online-submission.php \\
\hline
\end{tabular}

